\title{
Cough Modulation by Upper Airway Stimuli in Cat-Potential Clinical Application?
}

\author{
Ivan Poliacek ${ }^{1}$, Jana Plevkova², Teresa Pitts ${ }^{3}$, Zuzana Kotmanova1, Jan Jakus', \\ Michal Simera ${ }^{*}$ \\ ${ }^{1}$ Institute of Medical Biophysics, Jessenius Faculty of Medicine in Martin, Comenius University in Bratislava, \\ Martin, Slovakia \\ ${ }^{2}$ Institute of Pathophysiology, Jessenius Faculty of Medicine in Martin, Comenius University in Bratislava, \\ Martin, Slovakia \\ ${ }^{3}$ Department of Neurological Surgery, Kentucky Spinal Cord Injury Research Center, University of Louisville, \\ Louisville, USA \\ Email: "simera@jfmed.uniba.sk
}

Received 12 July 2016; accepted 19 August 2016; published 22 August 2016

Copyright (C) 2016 by authors and Scientific Research Publishing Inc.

This work is licensed under the Creative Commons Attribution International License (CC BY).

http://creativecommons.org/licenses/by/4.0/

(c) (i)

Open Access

\section{Abstract}

The modulation of mechanically induced tracheobronchial cough was tested by applying various stimuli and the elicitation of other airway protective behaviors in pentobarbital anesthetized cats. Capsaicin and histamine were injected in the nose, and mechanical nylon fiber and/or air puff stimulation was applied to the nose and nasopharynx. Reflex responses of cough, sneeze, aspiration reflex and expiration reflex were induced mechanically. Swallow was initiated by the injection of water into oropharynx. Subthreshold mechanical stimulation of nasopharyngeal and nasal mucosa, as well as water stimulation in the oropharynx and larynx, with no motor response, had no effect on rhythmic coughing. Cough responsiveness and excitability increased with capsaicin and air puff stimuli delivered to the nose. Vice versa, the number of cough responses was reduced and cough latency increased when aspiration reflexes $(>1)$ occurred before the cough stimulus or within inter-cough intervals (passive E2 cough phase). The occurrence of swallows increased the cough latency as well. Cough inspiratory and/or expiratory motor drive was enhanced by the occurrence of expiration reflexes, swallows, and sneezes and also by aspiration reflex within the inspiratory phase of cough and by nasal air puff stimuli. Complex central interactions, ordering and sequencing of motor acts from the airways may result in the disruption of cough rhythmic sequence but also in the enhancement of cough. Our data confirm that number of peripheral stimuli and respiratory motor responses significantly alters cough performance. We propose developing and testing stimulation paradigms that modify coughing and could be employed in correcting of inappropriate or excessive coughing.

\footnotetext{
${ }^{*}$ Corresponding author.
}

How to cite this paper: Poliacek, I., Plevkova, J., Pitts, T., Kotmanova, Z., Jakus, J. and Simera, M. (2016) Cough Modulation by Upper Airway Stimuli in Cat-Potential Clinical Application? Open Journal of Molecular and Integrative Physiology, 6, 35-43. http://dx.doi.org/10.4236/ojmip.2016.63004 
Keywords

Aspiration Reflex, Expiration Reflex, Sneeze, Swallow, Nasal Stimulation

\section{Introduction}

Airway protection and defense comprises the execution and coordination of several behaviors such as cough, apnea, sneeze, swallow, expiration and aspiration reflexes. In healthy airways, coordination of these responses results in the prevention and/or correction of aspiration into the lower airways/lungs [1].

Cough employs air compression and fast expiratory airflows to clean the airways. The effectiveness of cough is based on sufficient amount of air in lungs at the peak of coughing inspiration (I) and on forceful ballistic like activity of expiratory (E) pump muscles to execute the compression and expulsion [1] [2]. During the compression phase the expiratory muscles generate a force against the closed glottis, producing increased intraairway pressure. The accumulation of energy, in the compressive phase of cough, enhances the expulsive expiration and increases cleaning efficacy of the airways [1].

Hyperfunctional cough (i.e. chronic cough) can have various serious consequences on the cardiovascular and respiratory systems as well as on a quality of life [1] [3]. Hypofunctional cough and/or dystussia also has serious consequences on the ability to keep airways clean with significantly increased chance for aspiration pneumonia and more serious problems [4].

Among the reasons leading to inappropriate cough response there are increased and reduced primary cough afferent drive, inadequate cough modulation by secondary afferent inputs, and various central issues including serious central disorders such as Parkinson's disease, stroke etc. [5] [6]. Understanding of cough modulators may allow their employment in corrections of excessive or insufficient cough response improving pathological conditions of patients.

This paper summarizes and sorts our previous data, brings new results to light, and provides a theoretical base for pre-clinical studies targeting correction of inappropriate cough response in patients. We hypothesize that several procedures involving the stimulation of afferents additional to cough primary pathway may have potential to improve inappropriate cough performance in humans.

\section{Methods}

All our experiments were conducted on cats. Detailed description of experimental procedures has been provided in our previous reports [7]-[11]. Animal care as well as all procedures were performed in accordance with the Animal Welfare Guidelines of the Comenius University and the legislation for animal use and welfare of Slovak Republic and European Union (Directive 2010/63/UE). All protocols were approved by Ethic Commitee of Jessenius Faculty of Medicine.

Briefly, the cats ( $\mathrm{n}=101$, from eight series of experiments) were anesthetized by pentobarbital sodium (Spofa, Slovak Republic; Morbital, Polfa; Pfannenschmidt GmbH, Germany) and allowed to breath spontaneously (frequently, depending on $\mathrm{pO}_{2}$, an oxygen enriched air was delivered). Cough was induced by mechanical probing of the trachea down to the carina by a nylon fiber or a soft polyethylene catheter that had been moved back and forth and rotated (1/s). Sneezing was induced by gentle punctate mechanical stimulation of the nasal septum with an approximately $1.5 \mathrm{~cm}$ long soft nylon fiber. Aspiration reflex (AspR) was induced mechanically (soft nylon loop or air puff) in the nasopharynx via nasal approach or pharyngostomy. Expiration reflex (ExpR) was induced by nylon fiber loop or soft polyethylene catheter probing to the glottis (inferior vocal folds). Swallow was induced by the instillation of water into the oropharyngeal region (Figure 1). Control cough trials were performed before and after stimulation protocol with additional stimuli applied.

The cough reflex was defined by a large augmenting burst of diaphragm and/or parasternal EMG activity immediately followed (and partially overlapped) by a burst of expiratory abdominal EMG activity [1] [10] [12] with corresponding inspiratory-expiratory (I-E) oscillations of esophageal pressure (EP) as noted in Figure 2. Sneeze was distinguished from the cough reflex by activation of the styloglossus muscle during the expulsive phase, which matches the occurrence of ballistic-like abdominal discharge [10] [13].

Capsaicin ( $25 \mu \mathrm{l}, 50 \mu \mathrm{M}$, Sigma, dissolved in ethanol and diluted in buffered saline) and histamine (25 $\mu \mathrm{l}, 16$ 


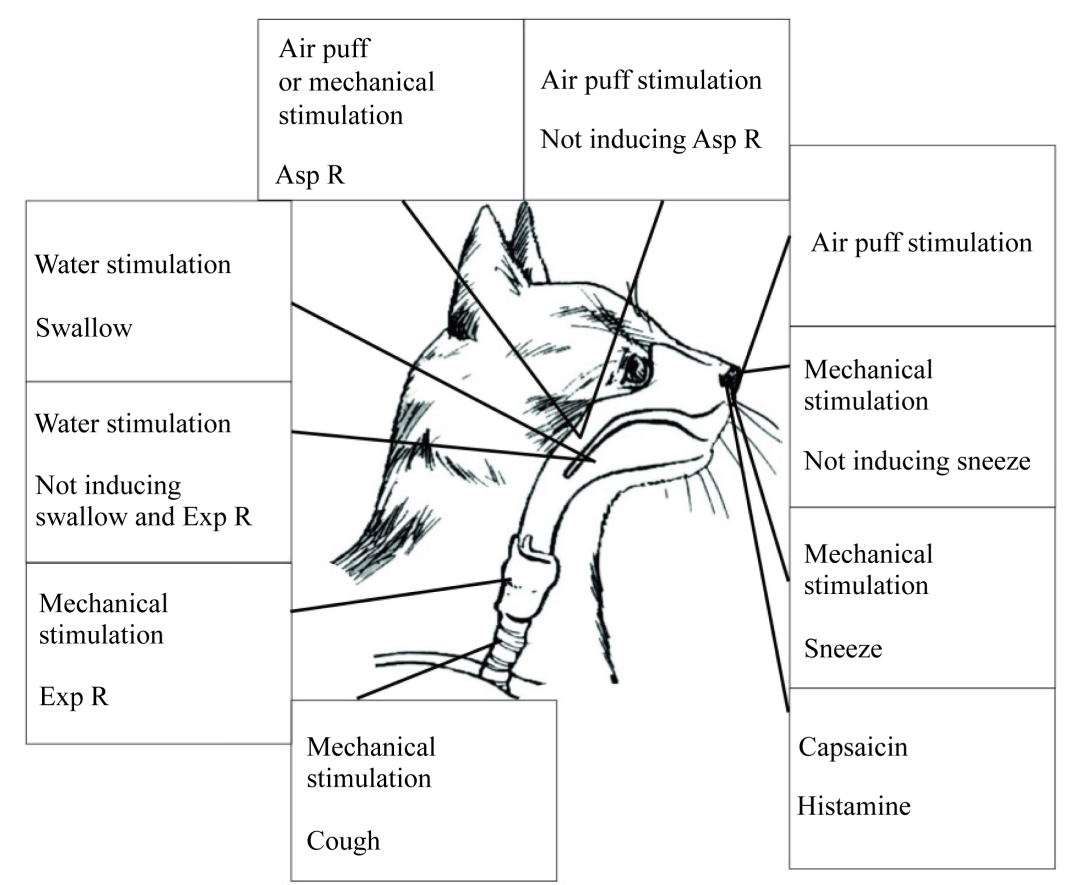

Figure 1. Schematics of stimulations, related stimulation sites and induced airway motor behaviors. Capsaicin initially inducing the sneeze reflex and histamine were injected to the nose, air-puff pressure pulses directed from the naspharynx to the nose and mechanical continuous stimulations inducing and not-inducing the sneeze reflex were applied in the nose. Mechanical tactile stimulation and air puff (some at subthreshold pressure with no motor response) eliciting aspiration reflex were delivered to the nasopharynx. Injection of water in oropharynx elicited swallow. Presence of water in pharynx and larynx was without motor response. Individual tactile mechanical stimuli to the glottis induced expiration reflex. Cough was produced by repetitive mechanical stimulation in the lower trachea.

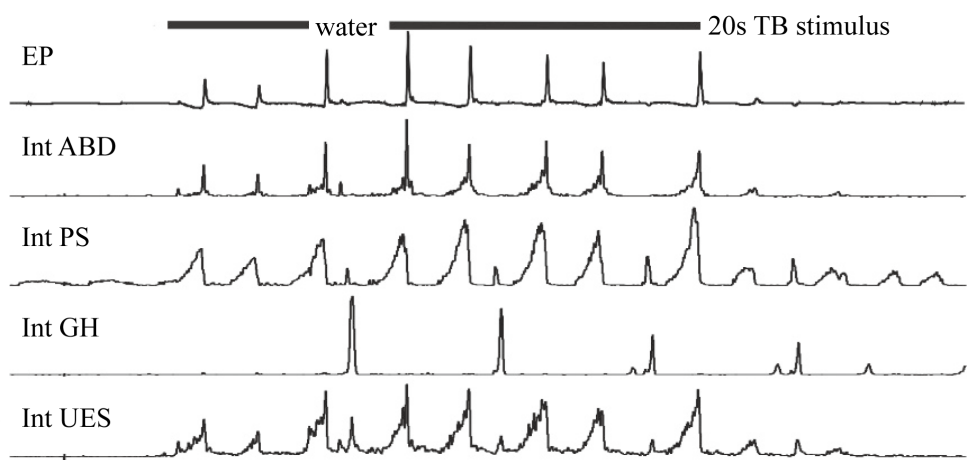

Figure 2. Water in oropharynx (water) induced swallows (depicted by a burst of geniohyoid muscle activity- GH and slight depression immediately followed by a burst of cricopharyngeus muscle = upper esophageal sphincter activity-UES) resulted in prolonged inter-cough intervals (latency to the following cough response) and increased cough motor drives. The number of cough efforts, however, was not significantly altered. Int, integrated activity (moving average); EP, esophageal pressure; ABD, abdominal muscle activity; PS, parasternal muscle activity.

mM, Biosynth, Riedel de Haen AG, Germany, diluted in buffered saline) challenges were performed by the instillation of solution into one nostril (lasting approximately $3 \mathrm{~s}$ ) via a thin plastic catheter inserted through the nose 7 - $8 \mathrm{~mm}$ from the nares (Figure 1). Tracheal stimulation began 10 - $15 \mathrm{~s}$ after administration of capsaicin or histamine in the nose. Nasal mucosa was cleaned with saline after completion of cough trial. The nasal air puff stimuli were delivered via catheter directed towards nasal cavity from the nasopharynx. 
Arterial blood pressure, respiratory rate, end-tidal $\mathrm{CO}_{2}$ concentration $\left(\mathrm{ETCO}_{2}\right)$ and body temperature were monitored and maintained within physiological range for each of the experimental conditions.

\section{Results}

In all protocols, including those with additional probing of airways, mechanical stimulation of the trachea/ bronchi reliably elicited repetitive cough. With the addition of mechanical stimulation, which resulted in a behavioral response (i.e. sneeze or AspR) and/or irritant stimulation to the nose, cough was significantly modulated [7]-[11]. Of note, sub-threshold mechanical stimulation either to the nasopharynx [7] [8] or nose (continuous stimulations) [10] or pharynx had no effect on any analyzed cough characteristics (Table 1).

Cough responsiveness (number of efforts/stimulation time) representing cough excitability was increased with the addition of capsaicin [11] or air puff stimulation to the nose (Table 1). Sneeze was elicited during the initial capsaicin administration to the nose in 77\% (10/13) of cats [11], but the air puff did not result in any elicited behavior. Of note, cough was only induced following the initial capsaicin adaptation period (i.e. sneeze no longer elicited) [11].

Cough responsiveness was reduced when AspR $(17.2 \pm 2.4)$ occurred just prior to coughor AspR (3.3 per period) were induced within inter-cough intervals (quiescent cough E2 phase) [7]. The effects correspond to prolonged latency to the first and subsequent coughs (prolongation of cough quiescent E2 phase duration; Table 1) [7]. E2 phase duration was also prolonged with the presence of swallow, however, with swallow there was no effect on number of coughs (Table 1; Figure 2) [9].

Table 1. Summary of cough modulation by additional afferent input or behavior induction.

\begin{tabular}{|c|c|c|c|c|c|c|}
\hline Stim/event & $\mathrm{CN}$ & latency & I drive & I EP & E drive & E EP \\
\hline nas mech & NS & NS & NS & NS & NS & NS \\
\hline nas $S n$ & NS & - & NS & NS & $+84 \%^{*}$ & $+54 \%{ }^{* *}$ \\
\hline nas caps & $+17 \%{ }^{*}$ & - & - & - & - & NS \\
\hline nas hist & NS & - & - & - & - & NS \\
\hline nas puff & $+41 \%^{*}$ & - & - & - & - & $+97 \%^{*}$ \\
\hline nph puff & NS & - & NS & NS & NS & NS \\
\hline AspR before & $-24 \%{ }^{*}$ & $+250 \%{ }^{*}$ & NS & NS & NS & NS \\
\hline AspR E2 & $-50 \%{ }^{* *}$ & $+183 \%{ }^{*}$ & NS & NS & NS & NS \\
\hline AspR I & NS & NS & $+72 \%{ }^{* *}$ & $+63 \%{ }^{* *}$ & $+44 \%{ }^{*}$ & $+38 \%{ }^{*}$ \\
\hline AspR E & NS & NS & NS & NS & NS & NS \\
\hline ExpR E2 & NS & NS & $+76 \%{ }^{* *}$ & $+45 \%{ }^{* *}$ & $+199 \%^{*}$ & $+66 \%{ }^{* *}$ \\
\hline ExpR I & NS & - & $+74 \%{ }^{* *}$ & $+29 \%{ }^{*}$ & $+148 \%{ }^{*}$ & $+108 \%{ }^{* *}$ \\
\hline ExpR E & NS & - & $+62 \%{ }^{*}$ & $+32 \%{ }^{* *}$ & $+275 \%^{*}$ & $+145 \%{ }^{* *}$ \\
\hline ph+lar w & NS & - & NS & NS & NS & NS \\
\hline orph Sw & NS & $107 \%{ }^{*}$ & $+22 \%{ }^{*}$ & NS & $+44 \%^{* * *}$ & $+63 \%^{*}$ \\
\hline
\end{tabular}

$\mathrm{CN}$ - cough number; latency — the duration from the stimulus to the beginning of the first cough, alternatively (for AspR E2 and orph Sw) inter-cough intervals = quiescent E2 phase of coughing; I drive — the diaphragm or parasternal muscle (for orph Sw) EMG moving average maximum; I EP-peak inspiratory esophageal pressure; E drive-the abdominal muscle EMG moving average maximum; E EP-peak expiratory esophageal pressure; nasmech—nasal mechanical stimulation not inducing motor response (sneeze); nas Sn—nasal mechanical stimulation that induced sneeze reflex; nas caps — nasal stimulation with capsaicin; nas hist—nasal stimulation with histamin; nas puff—nasal stimulation with air puff directed outward (expiratory);nph puff—nasopharyngeal air puff stimuli not inducing aspiration reflex; AspR—aspiration reflex; before-before cough trial begun, E2 during quiescent E2 phaseof cough; I-during cough inspiration; E-during inspiratory-expiratory transition or active E1 cough phase; ph+lar w-water stimulus within the pharynx and/or larynx when no swallow and/or expiration reflex has been induced; orph Sw-water stimulus in the oropharynx that induced swallow reflex; ${ }^{*} \mathrm{p}<0.05 ;{ }^{* *} \mathrm{p}<0.01 ;{ }^{* * *} \mathrm{p}<0.001$ compared to control coughing. 
During combined trials swallow, sneeze and cough (rhythmic behaviors) always occurred in an ordered sequence without significant overlapping of their motor activities [9] [10]. During sneeze/cough trials each behavior is either cough or sneeze [10] and they would be grouped together (i.e. several sneezes in a row followed by several coughs in a row). Swallow occurred (95\%) during the quiescent E2 phase of cough (termed phase restriction) [9]. Swallow also enhanced subsequent cough I and E components (Figure 2) [9]. Cooccurence of cough and sneeze resulted in increased cough E component (I and E component of sneeze) [10] and nasal air puff stimuli increased cough E, as well.

AspR and ExpR (short and immediate non-rhythmic responses) can occur during any phase of cough. Figure 3 demonstrates AspR transient inhibition of cough $\mathrm{E}$ with no change to the spatio-temporal cough feature [8]. However, AspR in the I phase of cough [8] and ExpR in any position (Figure 4) during coughing improved both I and E component of cough.

When number of cough was reduced due to applied stimuli, prolonged latency, quiescent E2 cough phase and total cough cycle durations were observed. The only altered active cough time interval was the cough expiratory period when AspR were induced during cough I [8].

\section{Discussion}

The cough reflex is an important mechanism of airways defense [1] [4] [12]. Cough's physiological significance is reinforced by its constancy under various and antagonistic conditions. Additionally, the present experimental data demonstrated that nasal stimulation, AspR, ExpR, sneezing and swallowing are able to enhance many parameters of cough performance [7]-[11] [14] [15]. These robust results prompt discussion of two major issues. First, potential mechanisms of cough modulation. These mechanisms could help to explain cough irregularities in many patient populations and allow for pharmacological interventions. Second, the use of these "experimental

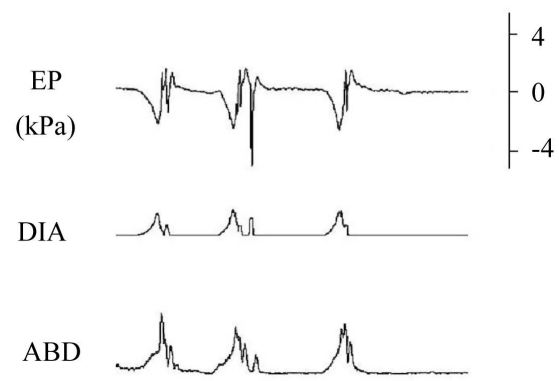

Figure 3. An example of aspiration reflexes within the expiratory phase of cough. They temporarily interrupt the course of cough expulsion-see breaks in the expiratory part of EP and ABD waveforms, however, without significant changes in cough spatiotemporal characteristics. For more details see [8]. EP, esophageal pressure; DIA, integrated (moving average) EMG activity of the diaphragm; ABD, integrated (moving average) EMG activity of the abdominal muscles.

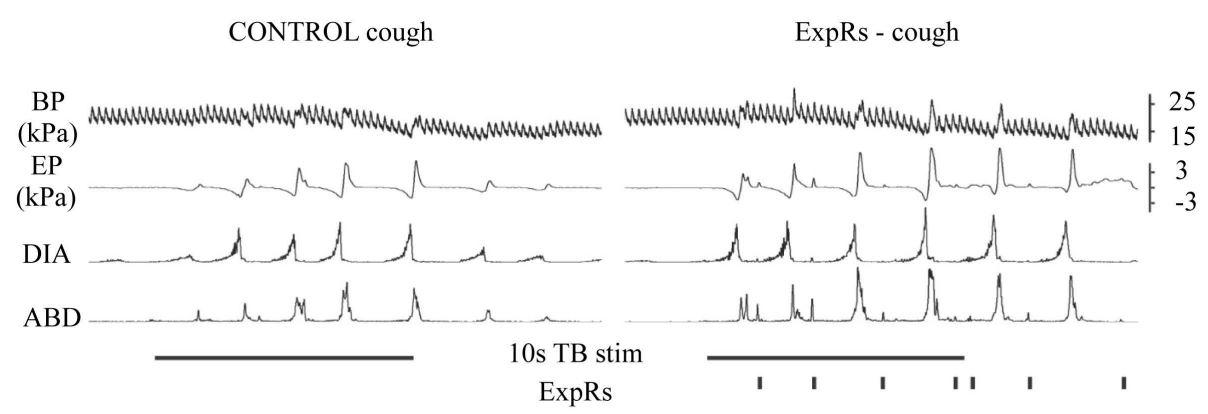

Figure 4. An example of effect of expiration reflexes (ExpRs) induced within the inter-cough intervals on the cough reflex on the right hand side (ExpRs-cough). Control cough stimulation is on the left hand side. BP, arterial blood pressure; EP, esophageal pressure; DIA, integrated (moving average) EMG activity of the diaphragm; ABD, integrated (moving average) EMG activity of the abdominal muscles. 
paradigms” as therapeutic interventions where modulations might be an effective course of treatment for cough irregularities [14] [15].

Our laboratories systematically analyzed cough under various conditions including: stimulations of additional afferent pathways and initiation of additional motor behaviors during coughing on experimental animals over decades. Based on the high number of reported experimental data, we hypothesize two functional levels for cough control [16] [17]. First, the cough motor pattern is generated by the central pattern generator (CPG); and second, the occurrence, ordering and appropriate placement of the motor act (including the inhibition of any other behavior) is provided by the behavioral control assembly [16]. According to this theory the subthreshold stimuli did not pass the "decision making filter" and were not effective in modulating cough excitability. As noted in Table 1, with the exception of the nasal air puff, all subthreshold stimulation was not able to significantly modulate the measured cough parameters.

Additionally, we hypothesize that the mechanism of cough modulation, by other simultaneously executed behaviors, is alterations in synaptic drive at the level of the CPG. The neuronal network involved in cough production extends over multiple areas of brainstem [18] [19]. High number of these neurons are multifunctional (i.e. they participate in multiple behaviors) [20] [21]. Thus, there is a high probability that the execution of one motor behavior (e.g. swallow) directly shares excitability with elements of cough network [22] [23].

AspR and ExpR are able to overlay onto the cough motor pattern (Figure 3). The mechanism for how this is possible remains unknown. Interestingly, AspR within cough E1 phase was able to temporarily interrupt the active expiratory phase (Figure 3), but it did not change EMG amplitude or phase durations [8]. AspRs (>1) within passive expiratory phase (E2) or pre-cough reduced cough responsiveness but also did not alter the cough motor pattern. On the other hand, AspRs during the inspiratory phase of cough enhanced cough I and E components. We hypothesized that higher volume related feedback (i.e. pulmonary stretch receptor activation) can increase the excitability for cough [8]. However, there is no relationship of volume-timing during cough [24], there arelimited correlations between I and E efforts/durations during cough [25], and the reduction of volume feedback increased I and E drive [26].

The up regulatory effect of ExpR on cough, regardless of cough phase, likely reflects increases in primary cough afferent drive [1]. It is consistent with increased cough response when higher intensity of stimulation (higher drive from receptors), larger area of stimulation, and multiple cough inducing sites including laryngeal and tracheal cough inducing areas are stimulated [27].

Capsaicin in the nose was able to modulate cough, while histamine did not have any significant effects [11]. This is likely due to the distribution of receptors and ion channels on related nasal sensory cells, target population of nasal sensory afferents and their connectivity to higher order neurons. Capsaicin, the agonist of TRPV1 receptors, is a powerful tussive agent. It induces cough responses from the larynx and tracheobronchial tree, and sneeze from the nasal mucosa [11] [28]. We expected little modulatory effect on cough from the sneeze responses that occurred immediately after application, because nasal capsaicin increased $\mathrm{CN}$ while sneeze reflexes during coughing enhanced cough expiratory efforts (Table 1) [11]. Histamine receptors H1-H4 are widely expressed in the nasal mucosa, however our experiments failed to show any significant modulation of cough response in cats. However, application of histamine to the nose of volunteers with allergic rhinitis enhances cough sensitivity. There are very likely inter-species differences in the response induced by histamine. Moreover, the anesthesia could cause the lack of the response in anaesthetized state in comparison with conscious subjects [29] [30].

The most significant feature of cough reduction was a longer latency to the first and/or subsequent coughs in the sequence. Increasing cough latency may represent practical technique for cough reduction in patient populations. Additionally, increased cough motor drive related to combinations of cough with swallow/sneeze could compensate for the trend of lowering cough number [15]. Such "compensation" could help increase airway protection by maintaining clear pharynx, while not recruiting cough [9] [17] [30]. This could represent behavioral target to reduce the sensation of needing to cough, without centrally suppressing the cough pattern generator with pharmaceutical agents.

There are other parallel afferent inputs and pathways modulating coughing besides those we summarized in this paper [31] [32]. Upper airways inflammatory diseases and gastro-esophageal reflux disease can up regulate cough [33] [34], while bronchopulmonary C-fiber activation [35], BP alterations [36] and perhaps irregular cough volumes stretch receptor activation [26] can decrease cough excitability and/or cough motor drive. We focused on those, which are easily applicable and inducible due to their potential employment for cough modu- 
lation in correction of excessive or insufficient coughing.

Number of peripheral stimuli and motor responses from the airways significantly alters cough performance. Complex central interactions, ordering and sequencing of motor acts may result in the disruption of cough rhythmic sequence but also in the enhancement of cough. We propose developing and testing stimulation paradigms that modify coughing and could be employed in correcting of inappropriate or excessive coughing.

\section{Acknowledgements}

This work was supported by the Slovak Research and Development Agency under the contract No. APVV0189-11, by VEGA 1/0253/15, 1/0072/16, 1/0107/14 and NIH National Heart, Lung, and Blood Institute HL109025, HL-107745.

\section{References}

[1] Korpáš, J. and Tomori, Z. (1979) Cough and the Other Respiratory Reflexes. Karger, Basel, 368 p.

[2] O’connor, R., Segers, L.S., Morris, K.F., Nuding, S.C., Pitts, T., Bolser, D.C., Davenport, P.W. and Lindsey, B.G. (2012) A Joint Computational Respiratory Neural Network-Biomechanical Model for Breathing and Airway Defensive Behaviors. Frontiers in Physiology, 3, 264. http://dx.doi.org/10.3389/fphys.2012.00264

[3] Morice, A.H., Fontana, G.A., Belvisi, M.G., Birring, S.S., Chung, K.F., Dicpinigaitis, P., Kastelik, J.A., Tatar, M. and Widdicombe, J.G. (2007) ERS Guidelines on the Assessment of Cough. European Respiratory Journal, 29, 1256-1276. http://dx.doi.org/10.1183/09031936.00101006

[4] Woodcock, A., Young, E.C. and Smith, J.A. (2010) New Insights in Cough. British Medical Bulletin, 96, 61-73. http://dx.doi.org/10.1093/bmb/ldq034

[5] Wheeler Hegland, K., Troche, M.S., Brandimore, A.E., Davenport, P.W. and Okun, M.S. (2014) Comparison of Voluntary and Reflex Cough Effectiveness in Parkinson’s Disease. Parkinsonism \& Related Disorders, 20, $1226-1230$. http://dx.doi.org/10.1016/j.parkreldis.2014.09.010

[6] Kulnik, S.T., Birring, S.S., Hodsoll, J., Moxham, J., Rafferty, G.F. and Kalra, L. (2016) Higher Cough Flow Is Associated with Lower Risk of Pneumonia in Acute Stroke. Thorax, 71, 474-475. http://dx.doi.org/10.1136/thoraxjnl-2015-207810

[7] Poliacek, I., Jakus, J., Simera, M., Barani, H., Visnovcova, N., Halasova, E. and Tomori, Z. (2009) Excitability and Rhythmicity of Tracheobronchial Cough Is Altered by Aspiration Reflex in Cats. Journal of Physiology and Pharmacology, 60, 105-110.

[8] Poliacek, I., Tomori, Z., Simera, M., Barani, H., Visnovcova, N., Halasova, E., Donic, V. and Jakus, J. (2009) Provocation of Aspiration Reflexes and Their Effects on the Pattern of Cough and Reflex Apnea in Cats. Journal of Physiology and Pharmacology, 60, 99-104.

[9] Pitts, T., Morris, K., Lindsey, B., Davenport, P., Poliacek, I. and Bolser, D. (2012) Co-Ordination of Cough and Swallow in Vivo and in Silico. Experimental Physiology, 97, 469-473. http://dx.doi.org/10.1113/expphysiol.2011.063362

[10] Simera, M., Poliacek, I., Dobrolubov, B., Veternik, M., Plevkova, J. and Jakus, J. (2015) Interactions of Mechanically Induced Coughing and Sneezing in Cat. Respiratory Physiology \& Neurobiology, 205, 21-27. http://dx.doi.org/10.1016/j.resp.2014.09.011

[11] Plevkova, J., Kollarik, M., Brozmanova, M., Revallo, M., Varechova, S. and Tatar, M. (2004) Modulation of Experimentally-Induced Cough by Stimulation of Nasal Mucosa in Cats and Guinea Pigs. Respiratory Physiology \& Neurobiology, 142, 225-235. http://dx.doi.org/10.1016/j.resp.2004.06.006

[12] Jakus, J., Tomori, Z. and Stransky, A. (2004). Neuronal Determinants of Breathing, Coughing and Related Motor Behaviours. Wist, Martin.

[13] Satoh, I., Shiba, K., Kobayashi, N., Nakajima, Y. and Konno, A. (1998) Upper Airway Motor Outputs during Sneezing and Coughing in Decerebrate Cats. Neuroscience Research, 32, 131-135. http://dx.doi.org/10.1016/S0168-0102(98)00075-3

[14] Vertigan, A.E., Kapela, S.L., Ryan, N.M., Birring, S.S., McElduff, P. and Gibson, P.G. (2016) Pregabalin and Speech Pathology Combination Therapy for Refractory Chronic Cough: A Randomized Controlled Trial. Chest, 149, 639-648. http://dx.doi.org/10.1378/chest.15-1271

[15] Chamberlain, S., Birring, S.S. and Garrod, R. (2014) Nonpharmacological Interventions for Refractory Chronic Cough Patients: Systematic Review. Lung, 192, 75-85. http://dx.doi.org/10.1007/s00408-013-9508-y

[16] Bolser, D.C., Poliaček, I., Jakuš, J., Fuller, D.D. and Davenport, P.W. (2006) Neurogenesis of Cough, Other Airway 
Defensive Behaviors and Breathing. A Holarchical System? Respiratory Physiology \& Neurobiology, 152, 255-265. http://dx.doi.org/10.1016/j.resp.2006.01.008

[17] Pitts, T., Rose, M.J., Mortensen, A.N., Poliacek, I., Sapienza, C.M., Lindsey, B.G., Morris, K.F., Davenport, P.W. and Bolser, D.C. (2013) Coordination of Cough and Swallow: A Meta-Behavioral Response to Aspiration. Respiratory Physiology \& Neurobiology, 189, 543-551. http://dx.doi.org/10.1016/j.resp.2013.08.009

[18] Jakuš, J., Poliaček, I., Halašová, E., Muríň, P., Knociková, J., Tomori, Z. and Bolser, D.C. (2008) Brainstem Circuitry of Tracheal-Bronchial Cough: C-Fos Study in Anesthetized Cats. Respiratory Physiology \& Neurobiology, 160, 289300. http://dx.doi.org/10.1016/j.resp.2007.10.014

[19] Gestreau, C., Bianchi, A.l. and Grelot, L. (1997) Differential Brainstem Fos-Like Immunoreactivity after LaryngealInduced Coughing and Its Reduction by Codeine. The Journal of Neuroscience, 17, 9340-9352.

[20] Jakuš, J., Tomori, Z. and Stránsky, A. (1985) Activity of Bulbar Respiratory Neurones during Cough and Other Respiratory Tract Reflexes in Cats. Physiologia Bohemoslovaca, 34, 127-136.

[21] Baekey, D.M., Morris, K.F., Nuding, S.C., Segers, L.S., Lindsey, B.G. and Shannon, R. (2004) Ventrolateral Medullary Respiratory Network Participation in the Expiration Reflex in the Cat. Journal of Applied Physiology, 96, 20572072. http://dx.doi.org/10.1152/japplphysiol.00778.2003

[22] Pitts, T., Morris, K.F., Segers, L.S., Poliacek, I., Rose, M.J., Lindsey, B.G., Davenport, P.W., Howland, D.R. and Bolser, D.C. (2016) Feed-Forward and Reciprocal Inhibition for Gain and Phase Timing Control in a Computational Model of Repetitive Cough. Journal of Applied Physiology, 121, 268-278. http://dx.doi.org/10.1152/japplphysiol.00790.2015

[23] Poliacek, I., Jakus, J., Simera, M., Veternik, M. and Plevkova, J. (2014) Control of Coughing by Medullary Raphé. Progress in Brain Research, 212, 277-295. http://dx.doi.org/10.1016/B978-0-444-63488-7.00014-8

[24] Bolser, D.C. and Davenport, P.W. (2000) Volume-Timing Relationships during Cough and Resistive Loading in the Cat. Journal of Applied Physiology, 89, 785-790.

[25] Wang, C., Saha, S., Rose, M.J., Davenport, P.W. and Bolser, D.C. (2009) Spatiotemporal Regulation of the Cough Motor Pattern. Cough, 5, 12. http://dx.doi.org/10.1186/1745-9974-5-12

[26] Poliacek, I., Simera, M., Veternik, M., Kotmanova, Z., Pitts, T., Hanacek, J., Plevkova, J., Machac, P., Visnovcova, N., Misek, J. and Jakus, J. (2016) The Course of Lung Inflation Alters the Central Pattern of Tracheobronchial Cough in Cat-The Evidence for Volume Feedback during Cough. Respiratory Physiology \& Neurobiology, 229, 43-50. http://dx.doi.org/10.1016/j.resp.2016.04.008

[27] Kondo, T. and Hayama, N. (2009) Cough Reflex Is Additively Potentiated by Inputs from the Laryngeal and Tracheobonchial Receptors and Enhanced by Stimulation of the Central Respiratory Neurons. Journal of Physiological Sciences, 59, 347-353. http://dx.doi.org/10.1007/s12576-009-0041-y

[28] Canning, B.J. and Mori, N. (2011) Encoding of the Cough Reflex in Anesthetized Guinea Pigs. American Journal of Physiology_Regulatory Integrative and Comparative Physiology, 300, R369-R377. http://dx.doi.org/10.1152/ajpregu.00044.2010

[29] Plevkova, J., Brozmanova, M., Pecova, R. and Tatar, M. (2006) The Effects of Nasal Histamine Challenge on Cough Reflex in Healthy Volunteers. Pulmonary Pharmacology \& Therapeutics, 19, 120-127. http://dx.doi.org/10.1016/j.pupt.2005.04.004

[30] Mazzone, S.B., Mori, N. and Canning, B.J. (2005) Synergistic Interactions between Airway Afferent Nerve Subtypes Regulating the Cough Reflex in Guinea-Pigs. Journal of Physiology, 569, 559-573. http://dx.doi.org/10.1113/jphysiol.2005.093153

[31] Hanacek, J., Tatar, M. and Widdicombe, J. (2006) Regulation of Cough by Secondary Sensory Inputs. Respiratory Physiology \& Neurobiology, 152, 282-297. http://dx.doi.org/10.1016/j.resp.2006.02.014

[32] Plevkova, J., Antosiewicz, J., Varechova, S., Poliacek, I., Jakus, J., Tatar, M. and Pokorski, M. (2009) Convergence of Nasal and Tracheal Neural Pathways in Modulating the Cough Response in Guinea Pigs. Journal of Physiology and Pharmacology, 60, 89-93.

[33] Plevkova, J. and Song, W.J. (2013) Chronic Cough in Subjects with Upper Airway Diseases_-Analysis of Mechanisms and Clinical Applications. Asia Pacific Allergy, 3, 127-135. http://dx.doi.org/10.5415/apallergy.2013.3.2.127

[34] Xu, X., Yu, L., Chen, Q., Lv, H. and Qiu, Z. (2015) Diagnosis and Treatment of Patients with Nonacid Gastroesophageal Reflux-Induced Chronic Cough. International Journal of Research in Medical Sciences, 20, 885-892. http://dx.doi.org/10.4103/1735-1995.170625

[35] Tatar, M., Nagyova, B. and Widdicombe, J.G. (1991) Veratrine-Induced Reflexes and Cough. Respiratory Medicine, 85, 51-55. http://dx.doi.org/10.1016/S0954-6111(06)80255-6

[36] Poliacek, I., Morris, K.F., Lindsey, B.G., Segers, L.S., Rose, M.J., Corrie, L.W., Wang, C., Pitts, T.E., Davenport, P.W. 
and Bolser, D.C. (2011) Blood Pressure Changes Alter Tracheobronchial Cough: Computational Model of the Respiratory-Cough Network and in Vivo Experiments in Anesthetized Cats. Journal of Applied Physiology, 111, 861873. http://dx.doi.org/10.1152/japplphysiol.00458.2011

\section{Submit or recommend next manuscript to SCIRP and we will provide best service for you:}

Accepting pre-submission inquiries through Email, Facebook, LinkedIn, Twitter, etc.

A wide selection of journals (inclusive of 9 subjects, more than 200 journals)

Providing 24-hour high-quality service

User-friendly online submission system

Fair and swift peer-review system

Efficient typesetting and proofreading procedure

Display of the result of downloads and visits, as well as the number of cited articles

Maximum dissemination of your research work

Submit your manuscript at: http://papersubmission.scirp.org/ 